\title{
Exploring the Relationship between Knowledge Integration and Process Improvement: A Case of Saudi Manufacturing Firms
}

\author{
Abdullah Mohammed Aldakhil ${ }^{1}$ \\ ${ }^{1}$ Associate Professor, Department of Management, College of Business, King Saud University, Saudi Arabia \\ Correspondence: Abdullah Mohammed Aldakhil, Associate Professor, Department of Management, College of \\ Business, King Saud University, P.O. Box 2459, Riyadh 11451, Saudi Arabia. E-mail: aaldakhil@hotmail.com \\ Received: December 3, 2020 \\ Accepted: January 6, 2021 \\ Online Published: January 11, 2021 \\ doi:10.5539/ijbm.v16n2p46 \\ URL: https://doi.org/10.5539/ijbm.v16n2p46
}

\begin{abstract}
Many scholars have explored the Knowledge Integration (KI) with the improvement of firm's performance. However, there is still scarcity of the literature available on integrating the knowledge and exploring process improvement of the firms, specifically the manufacturing firms operating in an emerging economy (Kingdom of Saudi Arabia KSA). The available literature focused on investigating and defining knowledge integration conceptually and ignored the need to investigate the knowledge integration. Therefore, this paper provides the guidelines for researchers, practitioners as well as policy makers about the integration of knowledge and its impact on process improvement. The paper explores a comprehensive understanding of knowledge integration with some motivational factors - Employee Empowerment and Recognition and Rewards. The paper provides significant contributions to Saudi-Manufacturing firms. The paper first, explores the literature that the manufacturing firms should understand before implementing the knowledge integration capabilities in their businesses. Second, it provides a successful framework for the Saudi-Manufacturing firms. Hypotheses are developed on the relationships among the KI (internal integration as well as external integration) and process improvement. The data is collected through a survey questionnaire from senior managers working in in Saudi Manufacturing firms and is analysed by using Structural Equation Modelling (SEM). The results have revealed that the firms implementing knowledge integration in their processes from supplier to customers are performing exceptionally well as compared to the other firms.
\end{abstract}

Keywords: knowledge integration, process improvement, recognition and rewards, employee empowerment, performance, manufacturing firms, kingdom of Saudi Arabia

\section{Introduction}

Knowledge integration is the backbone of every country and the developed countries focuses on managing the intellectual capital to build the knowledge economy. The firms can rely on internal as well as external integration of knowledge, however, it is argued that the knowledge integration is heavily dependent on motivational factors like teamwork, employee participation or engagement, recognition of employees and rewards for the employees. Knowledge integration is a critical capability, which may lead to process improvement which will ultimately improve the performance of the firm. It is obvious that, the success of any firm can be analysed on how well it manages and uses ideas, data and information which will later leads towards the knowledge of the firm. The small and large grocery stores now-a-days even uses the knowledge integration techniques by analysing the trends of customers buying habits and uses these in their stores. This is why, knowledge integration can be regarded as a substantial cradle of competitive advantage and perhaps an influential factor/variable which might play a significant role in improving the firm performance.

It is argued that, around $60 \%$ of the consultant firms found managing knowledge as an influential factor for the successfully commercialisation (Ofek \& Saravay, 2001). Basically, knowledge integration effects on the performance of the firm through its ability to competently develop the intellectual resources or assets, which are major sources of sustained competitive advantage (Abbas, J. 2020). Therefore, knowledge integration has the potential to integrate knowledge assets in a way that is difficult for competitors to duplicate. Knowledge integration becomes as an essential factor, which helps organizations to develop new products or services and to improve overall performance (Lee \& Yang, 2019). Knowledge of the firm is the most driving and strategic resource of every organisation (Nonaka \& Teece 2001), which is also essential to all activities, from production 
to marketing and will lead to competitive advantage for the firm. It is well analysed that the successful firms always focus on knowledge-related activities from supplier to production and to marketing in order to organize the entire knowledge integration processes and deliver the required information to the decision makers at the right time (Barthes \& Tacla, 2002). Knowledge as a word has a number of various interpretations. Researchers have defined knowledge from different perspectives. Knowledge is acquired by a corresponding experience, Churchman (1971) views knowledge as how members of the organization react to a collection of information; however, knowledge as information-sustained (or produced) belief. Wings (1993) describes knowledge as beliefs and truths, expectations, concepts, perspectives, and know-how and methodologies. Knowledge is the capacity to interpret and use information, and to find out which information is needed, which can be converted in knowledge management for the policy makers in the firms (Reem Mashat, 2020).

Knowledge can be further classified as subjective and objective knowledge; or explicit and tacit or implicit knowledge. Polanyi (1966) first parted human knowledge into two categories or dimensions: explicit and tacit knowledge. Explicit knowledge is the written document of formalized knowledge, expressed in different forms of manuals, textbooks, specifications or scientific formula. Therefore, explicit knowledge (also referred to as objective, impersonal or codified knowledge) may be articulated, and communicated in various systematic and formal languages. Also, it has been argued that information technology is the best way to present or display explicit knowledge (Yoo, 2006). Thus, explicit knowledge is made up of data and information that are captured in written and/or electronic formats. The second type of knowledge is tacit knowledge (also referred to as subjective or personal knowledge). Tacit knowledge is unformulated and action-based, highly personal and difficult to transfer and store (Nonaka, 1994). Therefore, tacit knowledge might not be documented, articulated and communicated, the most effective media to acquire and display tacit knowledge is people. Implicit knowledge is a form of tacit knowledge, implicit knowledge is the type of knowledge that is understood or shared by people or teams who are either unable or unwilling to express this knowledge explicitly without an appropriate atmosphere. Tacit knowledge requires efforts to bring it out in the organization.

The strategy of knowledge integration comprises the following aspects: policy, implementation, evaluation and monitoring. Such a policy aims to ensure that knowledge is available where and when needed and can be obtained from internal and external sources. However, knowledge integration infrastructure aims to make knowledge management activities simpler, faster, and more consistent and to reduce the cost and efforts to manage knowledge. Some examples of knowledge integration infrastructure are electronic databases, query systems, and web-based knowledge centres. Finally, knowledge integration practices include all capabilities and activities at the operational level that are designed and developed to directly manage organizational knowledge to meet particular goals and objectives (e.g. knowledge integration capability). Therefore, knowledge integration is an organizational capability developed to get the benefits of the acquired (either internal or external) knowledge.

\section{Theoretical Framework and Hypotheses Development}

To better understand knowledge integration (KI) in the manufacturing context, a research framework is developed, in which the model integrates the KI and its effect on process improvement. The framework presents a research model that moderates the knowledge integration and process improvement with dependent variables as employee empowerment (EE) and recognition \& rewards (RR).

\subsection{Employee Empowerment (EE) as a Source of Knowledge Integration}

Employee empowerment (EE) occurs in an environment in which employees have an influence on decisions and actions related to their jobs. Employee empowerment is a management (or an internal integration) practice that is implemented in many organizations at different levels. It is a philosophy about how employees and their knowledge are important in continuous improvement, knowledge integration processes and organizational success. Employee empowerment can be defined as an organizational process by which managers share their influences on decision-making with subordinates or the group (Marin-Garcia et.al. 2020; Belz, F. M., Binder, J. K. 2017). The importance of implementing a high level of employee empowerment has been discussed in several studies. For example, firms facing environmental uncertainty, such as increasing customer demands and deregulation, are encouraged to implement a high level of employee empowerment. Firms need to function as efficiently and effectively as possible to cope with such environmental uncertainty to remain competitive in the global market. Researchers indicate that implementing a high level of employee empowerment helps the organization and its employees to adjust to environmental changes and work conditions which will lead to more organizational flexibility and effectiveness (Delaney \& Sockell, 1990). Also, Gupta (2000) argued that more environmental uncertainty creates a need for a greater and faster flow of knowledge. Govindarajan (1988) argues 
that environmental uncertainty can be reduced by moving the decision-making level downward. Shifting the level of decision making to lower levels could increase access to information about the market. Furthermore, by implementing a higher level of employee empowerment, information can be obtained at a much faster rate.

H1. There is a significant and positive relationship between the Employee Empowerment (EE) level and the process improvement of the firm.

\subsection{Recognition and Rewards as a Source of Knowledge Integration}

In general, the alignment of rewards and objectives is an important managerial (and/or an internal integration) practice that enables the firm to acquire the employees knowledge and improve the firm's performance. Often, the term "recognition" and "rewards" refer to different concepts. Recognition is a non-financial award given to selected employees in appreciation of an outstanding level of accomplishment or behavior (Milne, 2017). Recognition can be seen as giving the workers input on what they have done right during their jobs. Based on this definition, this research finds that the alignment of recognition/rewards and organizational objectives is an important success factor for rewards systems. This research argues that alignment of recognition/ rewards and organizational objectives is an internal integration practice that helps to improve an organisation's effectiveness and knowledge base by influencing employee's behaviour. All organizations use promotions, pay, bonuses or other kinds of rewards to encourage a greater level of overall performance (Cameron \& Pierce, 1977). The literature agrees that incentives such as recognition and rewards are used to promote outstanding performance and encourage knowledge sharing and continuous learning. Recognition and rewards are dependent on the management's recognition of the subordinates' accomplishments. Within the literature it is clear that the difference between recognition and rewards is not always maintained. A large number of researchers use the term reward to cover both the terms. Thus, this research will use the term rewards to cover both recognition and rewards, taking into consideration the differences as needed.

H2. There is a significant and positive relationship between the Recognition and rewards and the process improvement of the firm.

\subsection{Relationship between Knowledge Integration and Process Improvement}

A firm's knowledge based resources are dispersed and distributed across the firm or may exceed the traditional firm's boundaries (Baldwin and Clark, 1997). The firm's performance and competitive advantage do not only depend on managing information and coordinating tasks, but also on integrating its dispersed specialized knowledge effectively and efficiently (Sambamurthy et al., 2001; Balsiger, 2016). Despite the wide agreement in the literature on the importance of knowledge in operational or manufacturing activities and the organization's role as a knowledge integrator, there is a lack of understanding about what processes form knowledge integration capability in the manufacturing context. (Battilana \& Le, 2014). Knowledge integration phenomenon remains conceptual, which means that knowledge integration capability lacks a precise and clear operational definition. One of the main objectives of this particular research is to define knowledge integration operationally through a comprehensive review of the literature. Working together with suppliers and customers and using information technologies to facilitate the integration processes are important themes of external integration. Successful organizations develop an external integration capability to meet customer requirements and solve problems through acquiring the required information and knowledge.

There is little agreement in the terminology of the literature on customer integration. Some refer to it as involvement, collaboration or partnering, and cooperation. Customer integration is accomplished in manufacturing firms to: acquire and incorporate more understanding of customers' requirements and needs (what customers prefer and why they prefer this?), establish relationships with customers (Swink \& Song, 2017), and modify internal activities to meet the customers' requirements (Kouftors et al., 2015). Common activities associated with establishing a higher degree of customer integration include customer satisfaction surveys, frequent customer contacts, and the interactions between the firm's employees and customers (Swink \& Song, 2017). Wong and Boon-itt, (2008) defined customer integration as the process of collaboration and interaction between a firm and its customers to ensure effective flow of supplies. They argued that in order for a firm to implement a high level of customer integration, the firm needs to explore the customer requirements deeply to be able to understand and improve its market, culture, organisation and products requirements deeply to be able to understand and improve its market culture, organisation and products so that it helps to respond rapidly to the customers' requirements. It is argued that the improvement of demand planning is another significant goal of customer integration and that without customer integration or information sharing, tremendous inefficiencies in customer service can occur. One of the early supporters of customer integration or involvement was Von Hippel (1988), who found that the customer is the key driver of innovation and improvement. Moreover, customers' 
input are not only a source of innovation but also of other organizational capabilities. They encouraged firms to involve customers to capture new knowledge and recognized the difficulties associated with customer involvement. However, they did not mention the importance of responding to customer requirements. For a manufacturer, customer integration means having the manufacturing capability to design and produce what the customer needs at the right time and with the right quality and price. Therefore, this research defines customer integration as the extent to which customer objectives are aligned with the organization's objectives to determine customer needs and actions and modify internal activities to meet these needs and actions.

The main benefits credited to customer integration are knowledge acquisition, complexity reduction and the establishment of cooperative relationships. Activities and organizational capabilities that promote customer integration enhance the diversity of functional skills and expertise. However, customer integration activities are not cheap. Organizations should compare the benefits that result from customer integration with the implementation level of customer integration. Because of this, some organizations are required to focus only on their relationship with key customers. This focus serves to reduce uncertainty and complexity and to clarify which capabilities are the most important. Empirical evidence has shown that supply chain integration is associated with high customer satisfaction, which in turn is associated with a higher performance of the firm. Rosenzweig et al. (2009) revealed associations between supply chain integration and some operational performances in terms of cost leadership, quality, process flexibility, and delivery reliability. Also, Baldwin, 2018 illustrated that organizations with the highest levels of integration practices had better reported development and improvement in various dimensions of manufacturing capabilities. Customer integration can support a differentiation strategy by providing better services, more understanding of customer requirements, collaborative communication, proactive quality, and other interaction. Therefore, a higher level of customer integration will result in superior and innovative quality products. Such products should lead to more profitability and performance. Recently, Benton and his colleagues mentions some examples of firms that improved their new-product development (NPD) process successfully by incorporating the voice of the customer into their processes (Benton, et al, 2020). The required designs for specific products are identified by customer integration practices to improve the steel conversion process and operational performance (Evans, 1996). As a result, as the knowledge of customers is embedded in the organizational knowledge, environmental uncertainty should be reduced.

H3: Knowledge Integration is positively related and responsible for the process improvement of the firm.

Based on the above explanation, this research proposes the following theoretical framework (Figure 1).

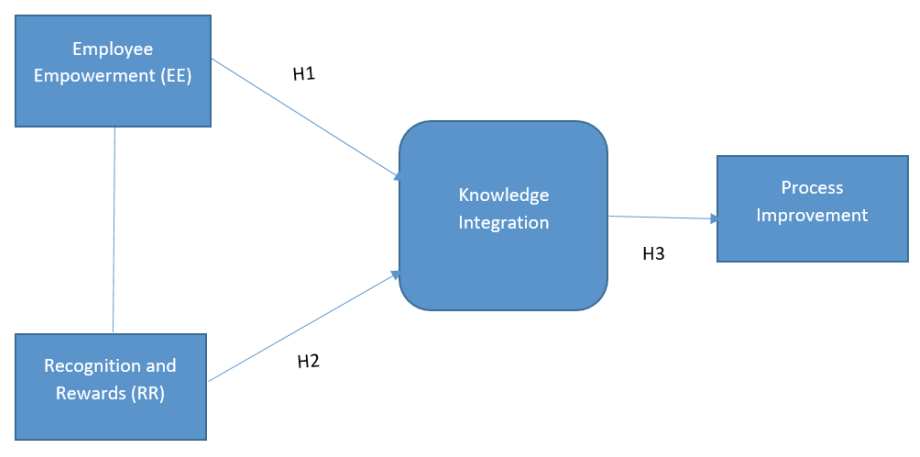

Figure 1. Theoretical framework

\section{Research Methodology}

\subsection{Data Sampling and Measurements}

The online survey methodology was conducted for data collection. This quantitative research method is adopted by developing a standardized questionnaire. In comparison of qualitative research methodology, a large-scale survey has an advantage of collecting diverse data from a varied body of organizations and industries in a relatively short period of time period. The online survey is chosen for the convenience and efficient research method. According to Bove et al (2016), the online-survey helps the researchers to be cost efficient and to collect required data in a short time period. Choosing the appropriate respondents is a very important aspect when designing a large-scale survey. The respondents are the individuals who have access to the organizational 
knowledge which is necessary in order to answer the questions on the survey. Therefore, in this research, the typical respondent is likely to be a president / CEO, a vice president, a general manager, a senior manager, or a plant manager.

\subsection{Data Analysis}

A total number of 350 individuals from different organisations are target respondents. A request to participate was sent to the target respondents by email, followed by telephonic calls and personal contacts. A total number of 244 responses were received, out of which 2 seemed to be outliners (either filled without reading or probably didn't understand the questions). Total number of useable respondents were 242 , which is about $70 \%$ of the targeted population. The demographic representations of the respondents is depicted in the following table.

Table 1. Demographic representations of the respondents

\begin{tabular}{lll}
\hline Job title & Response $\%$ & Response Count \\
\hline CEO/President & $7.4 \%$ & 18 \\
Director & $37.2 \%$ & 90 \\
Manager & $43.4 \%$ & 105 \\
Other & $11.98 \%$ & 29 \\
Total & $100 \%$ & 242 \\
\hline
\end{tabular}

\subsection{Analysis of PLS-SEM}

The results are presented here for testing of the research model. The proposed relationships among the constructs are evaluated by using partial least squares structural equation modelling (PLS-SEM) analysis. In (PLS-SEM) the strength of the hypothesised between the constructs or variables is tested and analysed through the (PLS-SEM) evaluation indicators (T-Value, Beta coefficient and $\mathrm{R}^{\wedge} 2$ ). The residual, $\mathrm{R}^{\wedge} 2$ values indicate the percentage of the explained variance of the dependant constructs (Kamel Gana and Guillaume Broc, 2019). The expected cut-off points are -0.19 and below (weak), between 0.19 and 0.33 is moderate, and 0.67 is substantial (Kamel Gana and Guillaume Broc, 2019). After a careful analysis, It is identified that $\mathrm{R}^{\wedge} 2$ values of are acceptable at early as well as later stages of the proposed model. The t-value is adopted to determine the significant level in the hypotheses developed. It could also be revealed that the significance level between the variables is also significant as proposed by Chae and her colleagues (Chae, S., Yan, T., \& Yang, Y. 2020). Moreover, t-values ranged between 1.6 and 2 predicates that the hypothesized relationship in the base model is significant. The cut-off value of beta coefficient is 0.20 , which can be considered as a trustful relationship between two variables. The following figure depicts the theoretical model, which consists of two independent variables, with one mediating variable and one independent variable. The model begins with these independent variables (Employee Empowerment (EE) and Recognition and Rewards (RR)), followed by the Knowledge Integration as mediating variable, and the consequences of Knowledge Integration (KI) conceptualized as process improvement (PI) of the firm. The results of the model are depicted in figure 2, model loadings are depicted $\mathrm{n}$ table 2, while summary of structural model results is tabulated in table 3 .

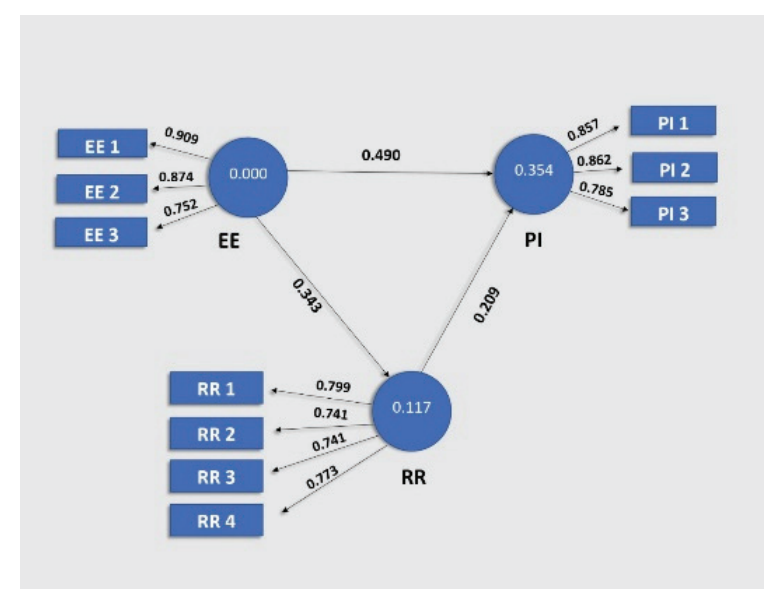

Figure 2. The measurements results 
Table 2. Model loadings

\begin{tabular}{lllll}
\hline Variables & Indicators & G Factor & AVE & Alpha \\
\hline Employee Empowerment & EE1 & 0.90 & & \\
(Marin-Garcia et.al. 2020; Belz, F. M., Binder, J. K. & EE2 & 0.87 & 0.71 & 0.79 \\
2017) & EE3 & 0.75 & & \\
& RR1 & 0.79 & & \\
& RR2 & 0.74 & 0.58 & 0.78 \\
Recognition and Rewards & RR3 & 0.74 & & \\
(Milne, 2017) & RR4 & 0.77 & & \\
& PI1 & 0.85 & & \\
Performance Improvement & PI2 & 0.86 & 0.55 & 0.79 \\
(Balsiger P , 2016) & PI3 & 0.78 & & \\
\hline
\end{tabular}

Table 3. Summary of structural model results

\begin{tabular}{llllll}
\hline Hypothesis & Relationship & $\mathrm{R}^{2}$ & Beta Coefficient & T-Values & Supported \\
\hline H1 & EE-KI-PI & 0.46 & 0.53 & 5.78 & Yes \\
H2 & RR-KI-PI & 0.31 & 0.56 & 5.7 & Yes \\
H3 & I-PI & 0.46 & 0.65 & 8.89 & Yes \\
\hline
\end{tabular}

\section{Discussions}

The structural equation model shown in the above figure suggests a significant relationship between process improvement and knowledge integration towards the independent factors. The statistical results are the beginning of the analysis and meant to facilitate and support the interpretation of the causal relationships among constructs. Therefore, each hypothesized relationship, whether or not statistically supported, needs to be justified by a theoretical rationale. More significantly, the theoretical and practical implications derived from the statistical results are well supported for each hypothesis. The results of the statistical analysis presented in the above table show negligible support for Hypothesis 1. The results indicate that employee empowerment (EE) directly impact the knowledge integration of the firm, which will lead towards the satisfactory improvement in the firm's processes, which will ultimately will improve the firm's performance as a whole. This means that implementing a high level of internal integration between teams to directly cope with the performance of the firm. This is one of the first empirical studies to examine the relationship between the employee empowerment and participation with the process improvement by utilising the knowledge as a mediator variable. This relationship was supported at the 0.001 level with a t-value of 5.86 and path coefficient of 0.58 . This implies that organization should empower their employees, so that they can perform better for the organisations. The statistical results support the contingency theory, which suggested that the organisation's actions will differ depending on the environmental nature it faces. The results of the statistical analysis provide support for hypothesis 3. The path coefficient between knowledge Integration (KI) and recognition and rewards (RR) is found to be highly significant and positive $(\mathrm{E}=0.65, \mathrm{t}=8.87)$. This indicates that $\mathrm{RR}$ has a direct and positive impact on the process improvement of the firm.

\section{Conclusions}

This paper explored the Saudi manufacturing firms, under some critical factors like- recognition and rewards, employee empowerment, by utilising the knowledge integration as a moderating variable. The hypotheses developed in the earlier sections of the paper were numerically tested and proved that these factors have a positive influence on the process improvement, which will ultimately improve the firm performance as a whole. There are no clear and operational definition of knowledge integration available in the literature and most empirical research in the field of operations management focuses on the conceptual aspects of knowledge integration and ignores the operational aspects of such capability. There are few studies, which have attempted to empirically investigate the concept of knowledge integration (KI), however, those studied have not clearly or specifically focused on the operationalising aspects of knowledge integration. This paper in particular, analysed some motivational aspects of knowledge integration and their impact on the process improvement of the firm. However, due to time and resources constraints the research could have provided a comprehensive investigation 
of how the firms can build effective knowledge integration capability by exploring the antecedents of knowledge integration and operationalising the aspects of knowledge integration capability.

\section{References}

Abbas, J. (2020). Impact of total quality management on corporate sustainability through the mediating effect of knowledge management. Journal of Cleaner Production, 244, 118806. https://doi.org/10.1016/j.jclepro.2019.118806

Baldwin, C. Y. (2018). Design rules, volume 2: How technology shapes organizations; chapter 6 the value structure of technologies (part 1). Boston, MA: Mapping Functional Relationships. Harvard Business School, Harvard Business School Research Paper Series. https://doi.org/10.2139/ssrn.3270932

Baldwin, C. Y., \& Clark, K. B. (1997). Managing in an age of modularity. Harvard Business Review, 75, 84-93.

Balsiger, P. (2016) The Fight for Ethical Fashion: The Origins and Interactions of the Clean Clothes Campaign. New York: Routledge. https://doi.org/10.4324/9781315558158

Barthes, J. A., \& Tacla, C. A. (2002). Agent-supported portals and knowledge management in complex. Rand Projects Computers in Industry, 48, 3-16. https://doi.org/10.1016/S0166-3615(02)00006-4

Battilana, J., \& Lee, M. (2014) Advancing research on hybrid organizing: Insights from the study of social enterprises. Acad. Management Ann., 8(1), 397-441. https://doi.org/10.5465/19416520.2014.893615

Belz, F. M., Binder, J. K. (2017). Sustainable entrepreneurship: A convergent process model. Business Strategy and the Environment, 26(1), 1-17. https://doi.org/10.1002/bse.1887

Benton, W. C., Skowronski, K., \& Hill, J. (2020). Perceived supplier poaching and shirking in outsourcing relationships in emerging economies. Journal of Operations Management, 66, 989-1023. https://doi.org/10.1002/joom.1123

Bové, A.-T., \& Swartz, S. (2016). Starting at the source: Sustainability in supply chains. McKinsey on Sustainability and Resource Productivity, 4, 36-43.

Cameron, J., \& Pierce, D. W. (1977). Rewards, interest and performance: an evaluation of experimental findings. American Compensation Association Journal, 6(4).

Chae, S., Yan, T., \& Yang, Y. (2020). Supplier innovation value from a buyer-supplier structural equivalence view: Evidence from the PACE awards in the automotive industry. Journal of Operations Management, 66, 820-838. https://doi.org/10.1002/joom.1063

Churchman, C. W. (1971). The Design of Inquiring Systems. New York, NY: Basic Books.

Delaney, J. T., \& Sockell, D. (1990). Employee involvement programs, unionization, and organizational flexibility. Proceedings of the Academy of Management, 264-268. https://doi.org/10.5465/ambpp.1990.4979662

Govindarajan, V. (1988). A contingency approach to strategy implementation at the businessunit level: Integrating administrative mechanisms with strategy. Academy of Management Journal, 31(4), 828-853. https://doi.org/10.2307/256341

Gupta, A. K., \& Govindarajan, V. (2000). Knowledge flows within multinational corporations. Strategic Management Journal, $21(4), \quad 473-496$. https://doi.org/10.1002/(SICI)1097-0266(200004)21:4\%3C473::AID-SMJ84\%3E3.0.CO;2-I

Kamel, G., \& Guillaume, B. (2019). Structural Equation Modeling with lavaan.

Koufteros, X., Vonderembse, M., \& Jayaram, J. (2015). Internal and external integration for product development: The contingency effects of uncertainty, equivocality, and platform strategy. Decision Sciences, 46(1), 97-133. https://doi.org/10.1111/j.1540-5915.2005.00067.x

Lee, C. C., \& Yang, J. (2019). Knowledge value chain. Journal of Management Development, 38(9), 783-793.

Marin-Garcia, J., Bonavia, T., \& Miralles, C. (2020). The use of employee participation in the USA and Spanish companies. International Journal of Management Science and Engineering Management, 15(4), 71-80. https://doi.org/10.1080/17509653.2008.10671037

Milne, Patricia., (2017). Motivation, incentives and organizational culture. Journal of Knowledge Management, 21(6), 28-38. https://doi.org/10.1108/13673270710832145

Nonaka, I. (1994). A dynamic theory of organizational knowledge creation. Organization Science, 5(1), 14-38. 
https://doi.org/10.1287/orsc.5.1.14

Nonaka, I., \& Teece, D. (2001). Managing industrial knowledge: creation, transfer and utilization. London: Thousand Oaks, Calif., SAGE.

Ofek, E., \& Saravay, M. (2001). Leveraging the customer base: creating competitive advantage through knowledge management. Management Science, 11(47), 1441-1456. https://doi.org/10.1287/mnsc.47.11.1441.10249

Polanyi, M. (1966). The Tacit Dimension. Routledge and Kegan Paul Ltd.

Reem, M. A. M. (2020). The Effect of the Use and Knowledge of AI on the Advanced Entrepreneurship in Saudis Small Business and Startups. International Journal of Business and Management, 15(12). https://doi.org/10.5539/ijbm.v15n12p35

Rosenzweig, E. D. (2009). A contingent view of e-collaboration and performance in manufacturing. Journal of Operations Management, 27, 462-478. https://doi.org/10.1016/j.jom.2009.03.001

Sambamurthy, V., Bharadwaj, A., \& Grover, V., (2001). Shaping agility through digital options: Re-conceptualizing the role of IT in contemporary firms. Working paper, University of Maryland, College Park, MD.

Swink, M., \& Song, M. (2017). Effects of marketing-manufacturing integration on new product development time and competitive advantage. Journal of Operations Management, 35, 203-217. https://doi.org/10.1016/j.jom.2006.03.001

Von Hippel, E. (1988). The Sources of Innovation. New York: Oxford University Press.

Wings, K. M. (1993). Knowledge management foundations: Thinking about thinking-how people and organizations create, represent, and use knowledge. Arlington, TX: Schema Press.

Wong, C., \& Boon-itt, S., (2008). The influence of institutional norms and environmental uncertainty on supply chain integration in the Thai automotive industry. Int. J. Production Economics, 115(2008), 400-410. https://doi.org/10.1016/j.jpe.2008.05.012

Yoo, D. K. (2006). Knowledge Management to Support Distributed Cognition and Behavior in Knowledge-Intensive and Computer-Mediated Work: A Manufacturing Perspective. Unpublished Ph. D. Dissertation, College of Business, University of Toledo.

\section{Copyrights}

Copyright for this article is retained by the author(s), with first publication rights granted to the journal.

This is an open-access article distributed under the terms and conditions of the Creative Commons Attribution license (http://creativecommons.org/licenses/by/4.0/). 